\title{
Does intravenous lidocaine infusion during video-assisted thoracoscopic surgery reduce postoperative analgesia? A randomized controlled study
}

\author{
Mark Slovack, MD • Brian Taylor, MD • \\ Rhonda Bryce, MD $\cdot$ Dennis Ong, MD
}

Received: 14 January 2015/Accepted: 30 January 2015/Published online: 11 February 2015

(C) Canadian Anesthesiologists' Society 2015

\section{To the Editor,}

Recent meta-analyses show that lidocaine infusions during open abdominal surgery reduce opioid consumption, postoperative ileus, and hospital length of stay; however, results in other surgeries have been conflicting. ${ }^{1-3}$ We conducted a single-centre double-blind randomized controlled trial to investigate whether intravenous lidocaine for video-assisted thoracoscopic surgery (VATS) would lower postoperative opioid requirements. Secondary outcomes included pain scores and side effects such as nausea, vomiting, pruritis, constipation, and symptoms of lidocaine toxicity, including lightheadedness, tinnitus, oral numbness, arrhythmias, altered mental status, or seizures. This trial is registered at ClinicalTrials.gov NCT01277835.

After approval from the Biomedical Research Ethics Board at the University of Saskatchewan on February 3, 2010, informed consent was obtained from adults aged 18-75 yr, American Society of Anesthesiologists physical status I-III, and scheduled for VATS from April 2010 to February 2013.

Computer randomization allocated patients into two groups according to a 1:1 ratio. The lidocaine treatment group received a $1.5 \mathrm{mg} \cdot \mathrm{kg}^{-1}$ bolus of intravenous lidocaine on induction, followed by an infusion of $3 \mathrm{mg} \cdot \mathrm{min}^{-1}$ for patients weighing $>70 \mathrm{~kg}$ or $2 \mathrm{mg} \cdot \mathrm{min}^{-1}$ for patients weighing $<70 \mathrm{~kg}$. The placebo group received a normal

\footnotetext{
M. Slovack, MD ( $₫) \cdot$ B. Taylor, MD · D. Ong, MD Department of Anesthesiology, Royal University Hospital, Saskatoon, SK, Canada

e-mail: mark.slovack@usask.ca

R. Bryce, MD

Clinical Research Support Unit, College of Medicine, University of Saskatchewan, Saskatoon, SK, Canada
}

saline bolus and an infusion to simulate the study drug. Anesthetic induction was standardized. Postanesthesia care unit (PACU) nurses administered morphine to keep the patients' numerical rating scale $<4$. All surgical team members (anesthesiologist, surgeon, and nurses) were blinded to the treatment groups.

Forty-eight patients were enrolled in the study. Complete data were available for 36 patients (19 lidocaine group; 17 control group) in this per-protocol analysis. Reasons for attrition of 12 patients included: surgical procedure converted to an open procedure (seven patients), failure to connect the lidocaine infusion (one), no data collected on the ward (one), and personal reasons (three). Demographic characteristics were similar between groups (Table). The Table also includes a summary of all study results with a comparison between groups for up to $48 \mathrm{hr}$ postoperatively. We found no statistically significant difference in intraoperative fentanyl use or morphine use in recovery. Postoperative morphine requirements and pain scores were low in both groups and not significantly different at any time.

There was no difference in occurrence of side effects, most of which were opioid related: nausea, constipation, urinary retention, and pruritis. One patient in the control group experienced respiratory depression not requiring invasive ventilation. In the PACU, one patient experienced blurry vision and lightheadedness and another experienced hypotension, both in the control group. There were no symptoms of lidocaine toxicity.

This trial suggests that an infusion of intravenous lidocaine during VATS procedures does not reduce opioid consumption in the operating room or postoperatively and does not reduce postoperative pain scores. This may be due in part to the relatively low consumption of morphine noted among our patients. Postoperative morphine consumption among VATS 
Table Characteristics and outcomes of treatment group $v s$ control group

\begin{tabular}{|c|c|c|c|c|}
\hline & & Treatment $(n=19)$ & Control $(n=17)$ & $P$ value* \\
\hline \multicolumn{2}{|l|}{ Age (yr) } & $58.0[45.0-74.0]$ & $65.0[58.5-71.0]$ & \\
\hline \multicolumn{2}{|l|}{$\mathrm{BMI}\left(\mathrm{kg} \cdot \mathrm{m}^{-2}\right)$} & $28.6[25.4-31.5]$ & $27.4[22.5-32.4]$ & \\
\hline \multicolumn{2}{|l|}{ Weight (kg) } & $79.4[73.4-97.5]$ & $81.6[67.3-97.5]$ & \\
\hline \multicolumn{2}{|l|}{ ASA physical status } & III [II-III] & III [II-III] & \\
\hline \multicolumn{2}{|c|}{ Local bupivacaine dose (mg) } & $20.0[16.0-20.0]$ & $20.0[14.5-20.0]$ & \\
\hline Sex & Male, $n(\%)$ & $13(68)$ & $8(47)$ & \\
\hline Tylenol/Naproxen & Yes, $n(\%)$ & $18(95)$ & $17(100)$ & \\
\hline \multirow[t]{2}{*}{ Infusion rate } & $2 \mathrm{mg} \cdot \min ^{-1}, n(\%)$ & $4(21)$ & $5(29)$ & \\
\hline & $3 \mathrm{mg} \cdot \min ^{-1}, n(\%)$ & $15(79)$ & $12(71)$ & \\
\hline Alexis O Port & Yes, $n(\%)$ & $2(11)$ & $7(41)$ & \\
\hline \multicolumn{2}{|c|}{ Total lidocaine dose (mg) } & $201.0(138.0-315.0)$ & 0 (control) & \\
\hline \multicolumn{5}{|l|}{ Opioid requirements } \\
\hline \multicolumn{2}{|c|}{ Total intraoperative fentanyl $(\mu \mathrm{g})$} & $250.0(200.0-305.0)$ & $250.0(212.5-385.0)$ & 0.26 \\
\hline \multicolumn{2}{|c|}{ PACU morphine (mg) } & $5.0[0-0.0]$ & $10.0[1.5-13.0]$ & 0.19 \\
\hline \multicolumn{5}{|c|}{ Cumulative PCA morphine (mg), } \\
\hline \multicolumn{2}{|l|}{ Post-op 8 hr } & $10.0[2.0-20.0]$ & $14.0[7.0-23.0]$ & 0.35 \\
\hline \multicolumn{2}{|l|}{ Post-op 16 hr } & $20.0[4.0-35.2]$ & $24.0[8.0-29.2]$ & 0.55 \\
\hline \multicolumn{2}{|l|}{ Post-op $24 \mathrm{hr}$} & $24.0[8.0-35.2]$ & $27.3[13.0-43.0]$ & 0.66 \\
\hline \multicolumn{2}{|l|}{ Post-op $48 \mathrm{hr}$} & $32.7[16.0-47.7]$ & $32.0[22.0-56.9]$ & 0.68 \\
\hline \multicolumn{5}{|l|}{ Side effects } \\
\hline \multicolumn{2}{|c|}{ At PCA start Yes, $n(\%)$} & $3(18)$ & $3(20)$ & $1.0^{\dagger}$ \\
\hline \multicolumn{2}{|c|}{ Subsequent Yes, $n(\%)$} & $6(33)$ & $6(35)$ & $0.81^{\dagger}$ \\
\hline
\end{tabular}

*Mann-Whitney U testing for continuous variables, Chi square for categorical variables ( ${ }^{\dagger}$ Fisher's exact test when $>20 \%$ of expected cell sizes $<5)$; Categorical variables are summarized with $n(\%)$; Continuous data are summarized with median [interquartile range]. ASA $=$ American Society of Anesthesiologists; BMI = body mass index; PACU = postanesthesia care unit; PCA = patient-controlled analgesia

patients has been reported at $57.4 \mathrm{mg}$ for the first $24 \mathrm{hr}^{4}$ Our results, 24-hr median morphine consumption of $24.0 \mathrm{mg}$ in the lidocaine group and $27.3 \mathrm{mg}$ in the control group, suggest that VATS might be less painful at our institution, which is more in keeping with another study reporting $24.7 \mathrm{mg}$ for the first $24 \mathrm{hr}^{5}$

Our results indicate that patients may not benefit from a lidocaine infusion during VATS. Given the small observed group differences and substantial variability, a very large number of subjects would be required to show statistically significant differences in morphine requirements, questioning clinical applicability.

Acknowledgements Thank you to Jennifer O'Brien for all the help in the study design, comments, and contribution to this article. Thank you to Dr. Punam Pahwa for advice provided as consulting biostatistician and to Masud Rana for statistical analysis. We also acknowledge the assistance of the Saskatoon Health Region.

Funding There are no sources of funding or conflicts of interest to declare.

\section{References}

1. McCarthy GC, Megalla SA, Habib ASI. Impact of intravenous lidocaine infusion on postoperative analgesia and recovery from surgery: a systematic review of randomized controlled trials. Drugs 2010; 70: 1149-63.

2. Vigneault L, Turgon AF, Cote $D$, et al. Perioperative intravenous lidocaine infusion for postoperative pain control: a meta-analysis of randomized controlled trials. Can J Anesth 2011; 58: 22-37.

3. Barreveld A, Witte J, Chahal H, Durieux ME, Strichartz G. Preventive analgesia by local anesthetics: the reduction of postoperative pain by peripheral nerve blocks and intravenous drugs. Anesth Analg 2013; 116: 1141-61.

4. Perttunen K, Nilsson E, Kalso E. I.v. diclofenac and ketorolac for pain after thoracoscopic surgery. Br J Anaesth 1999; 82: 221-7.

5. Ziser A, Messick JM, Schroeder DR, Allen MS. Requirements for postoperative analgesics in patients undergoing video-assisted thoracic surgery. The Internet Journal of Anesthesiology 1998; volume 3: number 2. Available from URL: https://ispub.com/IJA/ 3/2/13063 (accessed January 2015). 